\title{
ORGANIC AND TOTAL MERCURY DETERMINATION IN SEDIMENTS BY COLD VAPOR ATOMIC ABSORPTION SPECTROMETRY: METHODOLOGY VALIDATION AND UNCERTAINTY MEASUREMENTS
}

\author{
Robson L. Franklin* \\ Laboratório de Química Inorgânica, Companhia Ambiental do Estado de São Paulo, Av. Frederico Hermann Jr., 345, 05459-900 \\ São Paulo - SP, Brasil \\ Jose E. Bevilacqua \\ Diretoria de Tecnologia, Qualidade e Avaliação Ambiental, Companhia Ambiental do Estado de São Paulo, São Paulo / Centro de \\ Estudos Químicos, Centro Universitário FIEO, Av. Franz Voegeli, 300, 06020-190 Osasco - SP, Brasil
}

Deborah I. T. Favaro

Instituto de Pesquisas Energéticas e Nucleares, Av. Prof. Lineu Prestes, 2242, 05508-000 São Paulo - SP, Brasil

Recebido em 10/1/11; aceito em 1/6/11; publicado na web em 22/7/11

\begin{abstract}
The purpose of the present study was to validate a method for organic $\mathrm{Hg}$ determination in sediment. The procedure for organic $\mathrm{Hg}$ was adapted from literature, where the organomercurial compounds were extracted with dichloromethane in acid medium and subsequent destruction of organic compounds by bromine chloride. Total $\mathrm{Hg}$ was performed according to 3051A USEPA methodology. Mercury quantification for both methodologies was then performed by CVAAS. Methodology validation was verified by analyzing certified reference materials for total $\mathrm{Hg}$ and methylmercury. The uncertainties for both methodologies were calculated. The quantification limit of $3.3 \mu \mathrm{g} \mathrm{kg}^{-1}$ was found for organic $\mathrm{Hg}$ by CVAAS.
\end{abstract}

Keywords: sediments; organic mercury; CVAAS.

\section{INTRODUCTION}

Mercury is one of the most hazardous environmental pollutants and exists in a large number of physical and chemical forms with a large variety of properties that determine its complex distribution, biological enrichment and toxicity. ${ }^{1}$ Although all forms of mercury are poisonous, the ecological and human health effects are generally related to the environmental transformations of mercury into the toxic and biomagnification-prone compound methylmercury $(\mathrm{MeHg}) .^{2} \mathrm{The}$ methylation and demethylation processes often occur in sediments. This compartment acts as the source for mercury methylation, which subsequently leads to bioaccumulation. ${ }^{3}$ Therefore, the accurate and precise determination of $\mathrm{MeHg}$ in sediments is a key point to better understand the biogeochemical cycling of this contaminant and to estimate the associated exposures.

The organomercurial compounds are potentially more toxic than the inorganic forms of $\mathrm{Hg}$, being methylmercury $(\mathrm{MeHg}$ ) the compound present in greater amounts than other organic forms in the sediments, representing about $90 \%$ or more of these organic forms, depending on geochemical characteristics of the sediments. ${ }^{4-8}$

Ethyl and methylmercury affects the central nervous system and depending on the exposure time, symptoms may be irreversible and can eventually lead to death..$^{6-9}$

The term organic $\mathrm{Hg}$ has been used to include all the organomercurial compounds that are found in environmental samples such as methylHg, dimethylHg and phenylHg.

As other organometallic species, the analytical methods used for $\mathrm{MeHg}$ determination in sediments involve many steps. First, the solid sample must be extracted to secure the integrity of the mercury species present in the sample. Then, mercury species are separated and usually detected by atomic spectrometry (CVAAS and CVAFS) or mass spectrometry (GC-MS or ICP-MS) with or without a previous

*e-mail: robleocadio@hotmail.com preconcentration step. Different combinations of steps have been reviewed recently. ${ }^{10-12}$ However, such methods require sophisticated and costly equipment for an efficient separation and reliable quantification of organomercurial compounds.

Unfortunately, many Brazilian research centers and laboratories are not adequately structured for organomercurials quantification in geological samples. A simpler and cheaper CVAAS instrumentation along with an analytical procedure adapted for organomercurial compound analyses is a possible solution for organomercurial quantification in contaminated samples. Furthermore, INMETRO requires statistical tools such as uncertainty measurements for ABNT ISO 17025 laboratory accreditation. This accreditation certifies the laboratory as having the necessary scientific technical requirements.

The purpose of the present study was to adapt the methodology described by Bisinoti et al. ${ }^{13}$ based on the extraction of organic $\mathrm{Hg}$ forms with dichloromethane and $6 \mathrm{M}$ hydrochloric acid in sediments, followed by bromide chloride oxidation and stannous chloride as a reducing agent. The modifications in Bisinoti's procedure was to use $\mathrm{HCl} 2 \mathrm{M}$ instead of $6 \mathrm{M}$ and mercury quantification by CVAAS instead of CVAFS in order to provide a simpler and cheaper methodology for most Brazilian laboratories. This study also presented uncertainties sources that are associated with both total and organic $\mathrm{Hg}$ quantification. Certified reference material analyses were performed as well as part of the method validation by using IAEA 405 and BCR CRM 580 certified for total mercury and methylmercury. Analytical Quality Control (AQC) for the assessment of trueness of the analytical result was also performed. The accidental methylation (artifact) which can occur when analyzing organomercurial compounds was also investigated. The analytical procedure proposed in this study can be applied for environmental contaminated samples in any laboratory with CVAAS equipment. This paper further contributes for more reliable results and shows an uncertainty calculation measurement associated with organic $\mathrm{Hg}$ quantification. 


\section{EXPERIMENTAL}

\section{Organic mercury determination procedure}

The analytical method used for organic $\mathrm{Hg}$ quantification was adapted with some modifications from Bisinoti et al. ${ }^{13}$ and based on the extraction of organic $\mathrm{Hg}$ forms with dichloromethane and hydrochloric acid. Modifications consisted in altering the quantity and concentration of $\mathrm{HCl}$ used in the extraction step. Bisinoti used $5.0 \mathrm{~mL}$ of $\mathrm{HCl} 6.0 \mathrm{M}$ whereas this study used $15.0 \mathrm{~mL}$ of $\mathrm{HCl} 2.0 \mathrm{M}$. This alteration was done in order to avoid the accidental formation of organomercurial compounds that can occur in higher concentrations of $\mathrm{HCl}$ in samples characterized by high organic matter and high inorganic $\mathrm{Hg}$ contents. ${ }^{12,14,15}$ In the present study the preliminary results using BCR CRM 580 and IAEA 405 reference materials, the organic concentrations found were much higher than the certified values using $5 \mathrm{~mL}$ of $\mathrm{HCl} 6.0 \mathrm{M}$. IAEA 405 showed a variation of 9 to $12 \mu \mathrm{g} \mathrm{kg}^{-1}$ when compared to the $5.5 \mu \mathrm{g} \mathrm{kg}^{-1}$ certified value. For BCR CRM 580 the values fell between 97 and $115 \mu \mathrm{g} \mathrm{kg}^{-1}$, the certified reference value being $75 \mu \mathrm{g} \mathrm{kg}^{-1}$. The chemical recoveries were between 130 and $220 \%$ interval range. $\mathrm{EPA}^{16}$ acceptance criteria vary from 65 to $135 \%$ for aqueous solutions. Does the reduction of $\mathrm{HCl}$ concentration from 6 to $2 \mathrm{M}$ while maintaining the molar amount of $\mathrm{HCl}$ in the extraction and increasing the volume of $\mathrm{HCl}$ used from 05 to $15 \mathrm{~mL}$ was chosen.

A further alteration was to use a CVAAS detection system instead of CVAFS, more commonly found in Brazilian laboratories; however this change reflects the inability of quantifying the analyte in low concentrations. About 1.0 to $2.0 \mathrm{~g}$ of reference material or sample was weighed in glass flasks to which $15 \mathrm{~mL}$ of $2.0 \mathrm{~mol} \mathrm{~L}^{-1} \mathrm{HCl}$ (Merck) was added and put in an ultra-sound bath for $15 \mathrm{~min}$. After this, $15 \mathrm{~mL}$ of dichloromethane was added and the mixture agitated for at least $12 \mathrm{~h}$ at $150 \mathrm{rpm}$. The sample was then filtered using glass wool (CAAL) (previously treated with dichloromethane, $\mathrm{HCl}$ and deionized water, and heated in an oven), in order to separate sediment from its liquid phase. Centrifugation can be also used for this purpose. After this step, the dichloromethane phase was separated from the $\mathrm{HCl}$ phase in a separatory funnel. To the dichloromethane phase, containing all the organic compounds extracted from the sediments including all organomercurial compounds, $30 \mathrm{~mL}$ of $3.0 \%(\mathrm{v}, \mathrm{v})$ $\mathrm{HNO}_{3}$ (Merck) was added. This mixture was bubbled with ultrapure $\mathrm{N}_{2}$ gas (ECD level, from White Martins) for 20 min, approximately, and transferred to a $50 \mathrm{~mL}$ volumetric flask. To this flask, $400 \mu \mathrm{L}$ of bromine chloride solution (1.50 g of KBr (Merck) and $0.58 \mathrm{~g}$ of $\mathrm{KBrO}_{3}$ (Merck) in $100 \mathrm{~mL}$ conc. $\mathrm{HCl}$ ) was added and after $30 \mathrm{~min}$, $800 \mu \mathrm{L}$ of $30 \%$ hydroxylamine hydrochloride (Carlo Erba). Volume was completed to $50 \mathrm{~mL}$ with deionized water and again put in an ultra-sound bath for $10 \mathrm{~min}$. $\mathrm{Hg}$ determination was then performed by CVAAS using FIMS (Flow Injection Mercury System) from Perkin Elmer and stannous chloride $1.1 \%$ (m,v) (Merck) as a reducing agent.

\section{Total mercury determination procedure}

About $0.5 \mathrm{~g}$ of reference material was weighed directly in Teflon tubes, $10 \mathrm{~mL}$ of conc. $\mathrm{HNO}_{3}$ (Carlo Erba) was added and digestion carried out according to method EPA $3051 \mathrm{~A}^{17}$ and put into $50 \mathrm{~mL}$ volumetric flask. Total $\mathrm{Hg}$ determination was performed by CVAAS using FIMS from Perkin Elmer and 1.1\% (m,v) stannous chloride as a reducing agent.

\section{Calibration curve}

The calibration curve used for total and organic $\mathrm{Hg}$ quantification was prepared daily from a standard solution (Merck) traceable to NIST (National Institute of Standards and Technology, USA).

The micropipettes and the volumetric flasks used for preparation of intermediate standard solutions were calibrated by RBC (Rede Brasileira de Calibração). Table 1 presents the data of the calibration curve prepared. $\left(\mathrm{y}=69.87286^{*} \mathrm{x}-0.00388\right.$, with correlation coefficient $=0.99967$ ) by using FIMS from Perkin Elmer.

Table 1. Analytical curve prepared from $\mathrm{Hg}$ standard calibration solutions

\begin{tabular}{lcc}
\hline Point & $\begin{array}{c}\text { Expected concentration } \\
\left(\mu \mathrm{g} \mathrm{L}^{-1}\right)\end{array}$ & $\begin{array}{c}\text { Calculated concentration } \\
\left(\mu \mathrm{g} \mathrm{L}^{-1}\right)\end{array}$ \\
Calibration blank & 0.00 & \\
\hline S1 & $0.253 \pm 0.012$ & 0.2495 \\
S2 & $0.506 \pm 0.029$ & 0.4896 \\
S3 & $2.539 \pm 0.067$ & 2.618 \\
S4 & $5.036 \pm 0.090$ & 5.134 \\
S5 & $10.0 \pm 0.145$ & 9.989 \\
\hline
\end{tabular}

The calibration curves were prepared daily and two readings of each concentration value were taken. The calibration curve presented (Table 1) was that used for the calculations of quantification and detection limits. The minimum correlation coefficient value of 0.998 was the acceptance criterion for the calibration curves, with a confidence level of $95 \%$.

The "expected concentration" column presents the concentration of the prepared solutions with their respective uncertainties, while "calculated concentration" column presents the values obtained from the instrument calibration.

Three standard control solutions $(1.021 \pm 0.055 ; 2.552 \pm 0.074$ $4.082 \pm 0.099$, in this day), prepared and calculated daily, from another standard solution from Accustandard also traceable to NIST standard solution were used to confirm the concentration of the calibration curve. All solutions prepared for the calibration curve as well as standard control solutions were prepared in the same manner as the samples were, including the digestion procedure assisted by microwave oven in acid media in closed vessel, according to EPA 3015A. ${ }^{18}$

\section{Detection (DL) and quantification (QL) limits for total $\mathrm{Hg}$ determination}

Detection and quantification limits were determined taking into account the analytical curve (Table 1).

These limits were determined in the presence of analyte. The standard deviation is calculated as the lowest concentration of the analyte measurable by the analytical method. The detection limit is considered as three times the standard deviation value and the quantification limit, as ten times the standard deviation. To obtain this standard deviation value a three times dilution of the lowest concentration point in the calibration curve was made and the determination was performed immediately after dilution. The results are presented in Table 2.

As the acceptance criterion, the value of ten times the standard deviation $(10 * \mathrm{sd})$ must be higher than the mean of the individual measurements. In this case the detection limit was calculated as being $3 * 0.0085=0.0256 \approx 0.03 \mu \mathrm{g} \mathrm{L}^{-1}$. The quantification limit was calculated as being ten times the standard deviation $\left(10^{*} 0.0085\right.$ $\left.=0.085 \mu \mathrm{g} \mathrm{L}^{-1}\right)$, considering $0.10 \mu \mathrm{g} \mathrm{L}^{-1}$ as the DL value merely as a safety margin.

In the case of sediment samples prepared according to the US EPA procedure, ${ }^{17}$ a dilution factor of about 100 (0.5 g of sample in 
Table 2. Standard deviation of the lowest concentration determination of the analite (total $\mathrm{Hg})(\mathrm{n}=10)$

\begin{tabular}{ccc}
\hline Measurement & Signal & Concentration $\left(\mu \mathrm{g} \mathrm{L}^{-1}\right)$ \\
\hline 1 & 0.0009 & 0.0712 \\
2 & 0.0010 & 0.0740 \\
3 & 0.0012 & 0.0875 \\
4 & 0.0012 & 0.0791 \\
5 & 0.0013 & 0.0912 \\
6 & 0.0011 & 0.0745 \\
7 & 0.0011 & 0.0756 \\
8 & 0.0010 & 0.0721 \\
9 & 0.0013 & 0.0928 \\
10 & 0.0013 & 0.0894 \\
Mean (M) & & 0.0807 \\
Standard deviation (sd) & & 0.0085
\end{tabular}

$50 \mathrm{~mL}$ volumetric flask) should be considered. This means that the quantification limit for total $\mathrm{Hg}$ in sediment samples is $10 \mu \mathrm{g} \mathrm{kg}^{-1}$ or $0.01 \mathrm{mg} \mathrm{kg}^{-1}$.

\section{Detection (DL) and quantification (QL) limits for organic $\mathbf{H g}$ determination}

In this case, besides the DL and QL calculation for total $\mathrm{Hg}$ determination, one has to consider that the analytical procedure started with $1.5 \mathrm{~g}$ of sediment sample and final volume of $50 \mathrm{~mL}$, giving a dilution factor of 33. Therefore, for organic $\mathrm{Hg}$ determination in sediments, the LQ is $33 * 0.10=3.3 \mu \mathrm{g} \mathrm{kg}^{-1}$. Calculation was performed considering a wet sample. On a dry basis the LQ will be $10 \mu \mathrm{g} \mathrm{kg}^{-1}$, for a sample with $70 \%$ humidity.

\section{Uncertainty assessment for total $\mathrm{Hg}$ determination}

The acceptable interval presented in Table 3 corresponds to the standard uncertainty $(\mathrm{u})$ of these standard control solutions. The uncertainty assessment of a sample is defined as a parameter associated to the result of a measurement that characterizes the dispersion of values that can be fundamentally attributed to a measurand. ${ }^{19}$ The uncertainty assessment can be calculated from the known standard uncertainties of all factors of variability that influence the measurement. For instance, uncertainty of the standard solution given by the manufacturer, uncertainty of micropipette used in the solution preparation, uncertainty of the volumetric flask and the calibration of its volume, etc.

According to INMETRO,${ }^{20}$ the combined standard uncertainty " $u_{c}$ " can also be calculated from the square root of the sum of all variances of the process. Then the expanded uncertainty " $U$ ", for a 95\% significance level, can be obtained multiplying the combined uncertainty " $\mathrm{u}_{\mathrm{c}}$ " by an abrangency factor $(\mathrm{k})$ of 2 .

The analytical method for total $\mathrm{Hg}$ determination by CVAAS at CETESB has been assessed for all the parameters described above.
All the process and methodology variabilities were taken into account considering the variability of the last hundred values obtained for each one of the parameters, involving, among others, the uncertainty of the calibration standards. Thus, for calculation of combined uncertainty of the analytical results for total $\mathrm{Hg}$ determination in the present study, the relative standard deviation obtained from the mean of replicates and uncertainty measured from standard control solutions, are considered in the Equation 1:

$$
\begin{gathered}
u_{C}=\sqrt{s d^{2}+i c^{2}} \\
\text { and } \mathrm{U}=\mathrm{k} \mathrm{u}_{\mathrm{c}}
\end{gathered}
$$

where: $\mathrm{u}_{\mathrm{c}}$ - standard combined uncertainty; $\mathrm{sd}$ - standard deviation of the sample analysis; $i_{c}$-combined uncertainty of the procedure obtained by means of the standard control solutions.

The contribution $i_{c}$ is the mean of the uncertainties of the method calculated from historical data from standard control solutions, which is, $0.22 \mu \mathrm{g} \mathrm{L} \mathrm{L}^{-1}$, and includes the uncertainty of calibration standard.

This uncertainty value is practically linear for the constructed calibration curve. The uncertainty value for the $1.00 \mu \mathrm{g} \mathrm{L} \mathrm{L}^{-1}$ concentration value is that of $0.160 \mu \mathrm{g} \mathrm{L}^{-1}$. For the $2.50 \mu \mathrm{g} \mathrm{L}^{-1}$ concentration value the calculated uncertainty is $0.179 \mu \mathrm{g} \mathrm{L}^{-1}$ and for $4.00 \mu \mathrm{g} \mathrm{L}^{-1}, 0.216$ $\mu \mathrm{g} \mathrm{L}^{-1}$. The greater uncertainty value $\left(0.216 \mu \mathrm{g} \mathrm{L}^{-1}\right)$ was adopted for all quantification ranges.

The uncertainty of the analytical curve (that obtained from Table 1), whose calculations were performed by means of the minimum squares ( 0.044 for the highest concentration point) can be considered low when compared to the value obtained by the standard control solutions concentration variations and can be eliminated in Equation 1 and adopting this procedure it should be noted that the measurement of uncertainty near the method's quantification limit may be overestimated.

Therefore, the value of uncertainty calculated for total $\mathrm{Hg}$ will be the combination of the analytical methodology uncertainty considering the historical data of the standard control solutions with the standard deviation of replicates of sample analyses

\section{Uncertainty for the organic $\mathrm{Hg}$ determination}

For calculation of the uncertainty in the organic $\mathrm{Hg}$ determination procedure, besides the contributions already described for total $\mathrm{Hg}$ determination, there is one more variable and difficulty in the process this being the organic extraction phase. In this step various factors contribute for the uncertainty measurement, such as solvent partition coefficients, small temperature oscillations, vapor pressure of analyte and solvents, among others. Due to the complexity of the analytical procedure, mainly for identification and calculation of uncertainty sources in the organic extraction step, the uncertainty estimate was calculated by using the standard deviation (\%) in the reference material analyses, according to INMETRO.$^{20}$ For the IAEA 405, the certified value for $\mathrm{MeHg}$ is $5.49 \pm 0.53 \mu \mathrm{g} \mathrm{kg}^{-1}$ and for BCR $580,75 \pm 4 \mu \mathrm{g} \mathrm{kg}^{-1}$. These values are related to the $\mathrm{MeHg}$ content and not to the organic $\mathrm{Hg}$. The organic $\mathrm{Hg}$ concentration obtained by this procedure will always be higher or similar to the $\mathrm{MeHg}$ concentration.

Table 3. Results for the standard control solutions prepared as control in order to check the calibration curve (Table 1)

\begin{tabular}{lccc}
\hline & $\begin{array}{c}\text { Expected concentration } \pm \\
\text { uncertainty }\left(\mu \mathrm{g} \mathrm{L}^{-1}\right)\end{array}$ & $\begin{array}{c}\text { Calculated concentration } \\
\text { by FIMS } \pm \text { uncertainty }\left(\mu \mathrm{g} \mathrm{L}^{-1}\right)\end{array}$ & $\begin{array}{c}\text { Acceptance } \\
\text { interval }\end{array}$ \\
\hline Control 1 & $1.021 \pm 0.055$ & $1.030 \pm 0.223$ & $0.862-1.181$ \\
Control 2 & $2.552 \pm 0.074$ & $2.548 \pm 0.230$ & $2.374-2.730$ \\
Control 3 & $4.082 \pm 0.099$ & $4.10 \pm 0.23$ & $3.866-4.298$ \\
\hline
\end{tabular}


The expression for uncertainty estimation in the organic $\mathrm{Hg}$ determination will be described in Equation 2:

$$
\begin{gathered}
u_{C}=\sqrt{s d^{2}+((m d m r / 100) * V l)^{2}+i c^{2}} \\
\text { and } \mathrm{U}=\mathrm{ku}_{\mathrm{c}}
\end{gathered}
$$

being: $\mathrm{u}_{\mathrm{c}}$ - standard combined uncertainty for organic $\mathrm{Hg}$ determination; sd - standard deviation of the sample determination; mdmr - mean value of the standard deviation for the reference material analyses; $\mathrm{Vl}$ - determined value; $\mathrm{i}_{\mathrm{c}}$ - uncertainty combined for the methodology obtained through the mean of standard control solutions (already described).

The "mdmr" variable is a major contributor for the calculated uncertainty here presented. Its calculation is presented below.

\section{RESULTS AND DISCUSSION}

Standard control solutions presented the results shown in Table 3.

The acceptance interval for standard control solutions represents the standard uncertainty of these solutions, calculated according to INME$\mathrm{TRO}^{20}$ and is based on a confidence level of $95 \%$. In the first column of Table 3, the value and uncertainty expressed is of that of the solution preparation. The second column is obtained from the equipment with the combined uncertainty calculated according to Equation 1.

The results obtained through the standard control solutions within the acceptance interval indicated that the equipment was capable of quantifications within the constructed analytical curve (Table 1).

Blanks were analyzed $(\mathrm{n}=3)$ not only for total $\mathrm{Hg}$ quantification, but organic $\mathrm{Hg}$ as well. Both were prepared or extracted in the some way of the standard. Blank results for total $\mathrm{Hg}$ ranged from 0.007 to $0.012 \mu \mathrm{g} \mathrm{L}^{-1}$ and to organic Mercury between 0.01 a $0.02 \mu \mathrm{g} \mathrm{L}^{-1}$.

The analytical methodology for $\mathrm{Hg}$ speciation (in organic mercury and inorganic mercury) in environmental samples developed in this study can be applied in laboratories without any sophisticated equipment for $\mathrm{Hg}$ determination, only a CVAAS is needed. The QL obtained by using this analytical method $\left(3.3 \mu \mathrm{g} \mathrm{kg}^{-1}\right)$ is not too low when compared to literature values but it can be easily employed in sediment samples which are contaminated with $\mathrm{Hg}$.

Analytical quality control (AQC) for the assessment of trueness of the analytical result

Reference material analyses was performed in the BCR CRM 580 (total and methylmercury in estuarine sediment) and IAEA 405 (estuarine sediment) reference materials for both, total and organic $\mathrm{Hg}$ in order to verify the accuracy of both analytical methods. The results obtained for all determinations of reference materials are shown in Tables 4 and 5. The recovery factors were $96.3 \%$ for total $\mathrm{Hg}\left(0.78 \pm 0.07 \mathrm{mg} \mathrm{kg}^{-1}\right)$ and $106.6 \%$ for $\mathrm{MeHg}\left(5.8 \mu \mathrm{g} \mathrm{kg}^{-1} \pm 1.0\right.$ as sd) determined as organic $\mathrm{Hg}$ for the IAEA 405 and $96.2 \%$ for the total $\mathrm{Hg}\left(127 \pm 7 \mathrm{mg} \mathrm{kg}^{-1}\right)$ and $84.8 \%\left(64 \mu \mathrm{g} \mathrm{kg}^{-1} \pm 13\right.$, as sd), for the BCR CRM 580.

As we can observe the chemical recovery for the BCR CRM 580 reference material ranged from 64.1 to $112.3 \%$. The mean value obtained for 11 determinations for organic $\mathrm{Hg}$ was lower than the certified value $\left(75 \pm 4 \mu \mathrm{g} \mathrm{kg}^{-1}\right)$, showing a relative standard deviation of $20.9 \%$ and relative error of $15.2 \%$.

For the IAEA 405 reference material, the chemical recovery ranged from 76.4 to $135.2 \%$ and the mean value for 11 determinations of organic $\mathrm{Hg}$ was higher than the certified value (5.49 \pm 0.53 $\mu \mathrm{g} \mathrm{kg}^{-1}$ ), showing a relative standard deviation of $17.9 \%$ and relative error of $6.6 \%$.

As acceptance criteria of recovery percentages were those recog-
Table 4. Results for organic $\mathrm{Hg}$ in BCR CRM $580\left(75 \pm 4 \mu \mathrm{kg}^{-1}\right.$ as $\left.\mathrm{Me} \mathrm{Hg}\right)$

\begin{tabular}{lcccc}
\hline & $\begin{array}{c}\text { Determined } \\
\text { Value } \\
\left(\mu \mathrm{g} \mathrm{kg}^{-1}\right)\end{array}$ & $\begin{array}{c}\text { Standard } \\
\text { deviation } \\
\left(\mu \mathrm{kg}^{-1}\right)\end{array}$ & $\begin{array}{c}\text { Absolute } \\
\text { error }\end{array}$ & $\begin{array}{c}\text { Chemical } \\
\text { recovery }(\%)\end{array}$ \\
\hline 77.9 & 0.6 & -2.9 & 103.9 \\
& 84.2 & 0.4 & -9.2 & 112.3 \\
& 60.5 & 0.7 & 14.5 & 80.7 \\
& 48.5 & 0.6 & 26.5 & 64.7 \\
& 53.3 & 1.1 & 21.8 & 71.0 \\
& 74.5 & 0.6 & 0.5 & 99.4 \\
& 48.3 & 1.3 & 26.7 & 64.3 \\
& 58.7 & 0.4 & 16.3 & 78.3 \\
& 48.0 & 3.5 & 27 & 64.0 \\
Mean & 70.3 & 0.2 & 4.7 & 93.8 \\
Std dev & 75.4 & 3.9 & -0.4 & 100.5 \\
Relative std dev (\%) & 63.6 & & 11.4 & 84.8 \\
Relative error $(\%)$ & 13.3 & & 13.3 & 17.8 \\
\hline
\end{tabular}

Table 5. Results for organic Hg in the IAEA 405 reference material (5.49 \pm $0.53 \mu \mathrm{g} \mathrm{kg}^{-1}$ as $\mathrm{MeHg}$ )

\begin{tabular}{lcccc}
\hline & $\begin{array}{c}\text { Determined } \\
\text { value } \\
\left(\mu \mathrm{g} \mathrm{kg}^{-1}\right)\end{array}$ & $\begin{array}{c}\text { Standard } \\
\text { deviation } \\
\left(\mu \mathrm{g} \mathrm{kg}^{-1}\right)\end{array}$ & $\begin{array}{c}\text { Absolute } \\
\text { error }\end{array}$ & $\begin{array}{c}\text { Recovery } \\
(\%)\end{array}$ \\
\hline 5.29 & 0.67 & 0.20 & 96.4 \\
& 4.19 & 0.35 & 1.30 & 76.4 \\
& 4.89 & 0.33 & 0.60 & 89.1 \\
& 5.98 & 0.91 & -0.49 & 109.0 \\
& 7.37 & 0.70 & -1.88 & 134.3 \\
& 7.04 & 0.21 & -1.55 & 128.3 \\
& 5.21 & 0.29 & 0.28 & 94.9 \\
& 5.32 & 0.33 & 0.17 & 96.9 \\
& 5.60 & 0.89 & -0.11 & 102.1 \\
& 7.42 & 0.62 & -1.93 & 135.2 \\
Mean & 6.06 & 0.27 & -0.57 & 110.4 \\
Std dev & 5.85 & & -0.36 & 106.6 \\
Relative std dev $(\%)$ & 1.05 & & 1.05 & 19 \\
Relative error $(\%)$ & 6.6 & & & \\
\hline
\end{tabular}

nized by the US EPA ${ }^{16}$ for spike in aqueous solutions which define an acceptable range between 65 and $135 \%$ of recovery.

\section{Interference assessment in the organic Hg extraction}

\section{Inorganic $\mathrm{Hg}$}

Methylmercury chloride solution (Aldrich) was prepared in several concentrations (in $\mu \mathrm{g} \mathrm{L}^{-1}$ ) in 1.0 to $5.0 \mathrm{mg} \mathrm{L}^{-1}$ of inorganic $\mathrm{Hg}$ solutions (Accustandard). $\mathrm{MeHg}$ was determined using the analytical procedure for organic $\mathrm{Hg}$ determination in order to verify if the method could also transfer some inorganic $\mathrm{Hg}$. The results obtained are shown in Table 6 and correspond to an average recovery of $97.8 \%$. 
Table 6. Results obtained for $\mathrm{MeHg}$ determination and recovery

\begin{tabular}{|c|c|c|c|c|c|}
\hline & MeHg expected concent. $\left(\mu \mathrm{g} \mathrm{L}^{-1}\right)$ & Obtained value $\left(\mu \mathrm{g} \mathrm{L}^{-1}\right)$ & Standard Deviation & Absolute error & Recovery (\%) \\
\hline & 9.6 & 8.8 & 0.38 & 0.81 & 91.5 \\
\hline & 11.4 & 12.3 & 0.36 & -0.9 & 107.9 \\
\hline & 16.9 & 16.4 & 1.02 & 0.59 & 96.5 \\
\hline & 11.6 & 11.3 & 0.12 & 0.3 & 97.4 \\
\hline & 10.7 & 9.0 & 0.45 & 1.72 & 84.0 \\
\hline & 12.4 & 13.9 & 0.76 & -1.46 & 111.7 \\
\hline Mean & & & & 0.18 & 98 \\
\hline Standard Deviation & & & & 1.17 & 10 \\
\hline
\end{tabular}

Blank analyses indicated $\mathrm{Hg}$ concentration levels below $0.1 \mu \mathrm{g} \mathrm{\textrm {L } ^ { - 1 }}$. No inorganic $\mathrm{Hg}$ transfer was observed.

The approximate $10 \mu \mathrm{g} \mathrm{L}^{-1}$ concentration was chosen randomly. This experiment was carried out only to verify any possible inorganic $\mathrm{Hg}$ methylation during the extraction process.

The standard deviation values obtained in the reference material analyses and the $\mathrm{MeHg}$ chloride recoveries in relation to the absolute value compose the variable "mdmr" in Equation 2, used to determine the uncertainty assessment for organic $\mathrm{Hg}$ quantification in this study.

Looking again at Equation 2 for uncertainty calculation, the variable "ic" has a fixed constant value of $0.22 \mu \mathrm{g} \mathrm{L}^{-1}$. The value for "mdmr" variable for Equation 2, is the square root of the sum of all standard deviation values obtained for the reference material analyses and $\mathrm{MeHg}$ chloride standard or

$$
\sqrt{1,05^{2}+1,17^{2}+13,34^{2}}=13,4 \mu \mathrm{g} \mathrm{L^{-1 }}
$$

The results shown in Table 4 to 6 confirm the validation of the analytical procedure used for extraction of organic $\mathrm{Hg}$ from sediments. The mean recovery $(\%)$ in the reference material analyses as well as $\mathrm{MeHg}$ chloride determination (84 to $112 \%$ ) were both within the acceptable range recommended by the US EPA according to the 1630 method $^{16}$ for the extraction of standard additions of $\mathrm{MeHg}$ in aqueous matrices. US EPA defined the ideal recovery as being between 65 and $135 \%$, with the maximum standard deviation of $31 \%$. There were some recovery values below $65 \%$ for the reference material BCR CRM 580 (64.0 and $64.7 \%$ ). These values were considered acceptable due to the fact that the criteria have been established for aqueous solutions and not for sediments. It is important to note that this procedure is related to organic $\mathrm{Hg}$ determination.

These results also indicate that the methodology is within the acceptable ranges in regards to accidental methylation which can occur when analyzing organomercurial compounds. Several authors ${ }^{11-15,21-24}$ cite the accidental $\mathrm{MeHg}$ formation as one of the main problems in determining this analite and consequently in the organic $\mathrm{Hg}$ determination. According to these authors, the $\%$ of $\mathrm{Hg}^{+2}$ methylated is low (up to $0.5 \%$, but normally between 0.01 to $0.05 \%$ in relation to $\mathrm{Hg}^{+2}$ ).

The positive error in the $\mathrm{MeHg}$ concentration due to this effect is important only when the relationship between $\mathrm{MeHg}$ and inorganic $\mathrm{Hg}$ in the sample is $<1 \%$. This occurs in some polluted sediments and residual waters, depending on the quantity of $\mathrm{Hg}^{+2}$ and methylation potential of the sample, which also depends mainly on organic matter content. ${ }^{12,14,15,22,23}$ Then the methylation contribution was not considered in this study once is too low.

Table 7 presents the results obtained in the reference material analyses for total $\mathrm{Hg}$ using the experimental procedure according to the US EPA 3051A.

The recovery factors for total $\mathrm{Hg}$ were $96.2 \%$ for the BCR CRM $580\left(127 \pm 17 \mathrm{mg} \mathrm{kg}^{-1}\right)$ and $96.3 \%\left(0.78 \pm 0.07 \mathrm{mg} \mathrm{kg}^{-1}\right)$ in the IAEA
Table 7. Reference material analyses results ( \pm uncertainty) for total $\mathrm{Hg}$ by CVAAS

\begin{tabular}{lcc}
\hline Reference Materials & BCR 580 & IAEA 405 \\
\hline Total Hg certified value & $132 \pm 6$ & $0.81 \pm 0.04$ \\
$\left(\mathrm{mg} \mathrm{kg}^{-1}\right)$ & $103 \pm 6$ & $0.67 \pm 0.09$ \\
& $144 \pm 7$ & $0.82 \pm 0.09$ \\
Total Hg obtained $\left(\mathrm{mg} \mathrm{kg}^{-1}\right)(\mathrm{n}=5)$ & $142 \pm 6$ & $0.76 \pm 0.08$ \\
& $129 \pm 5$ & $0.79 \pm 0.06$ \\
Mean & $118 \pm 5$ & $0.86 \pm 0.08$ \\
Standard deviation & 127 & 0.78 \\
Relative standard deviation (\%) & 13.4 & 0.07 \\
Relative error $(\%)$ & 3.8 & 9.0 \\
\hline
\end{tabular}

405. The relative standard deviation was 13.4 and $9.0 \%$ and bias, 3.8 and $3.7 \%$, respectively, showing the accuracy of the analytical methodology.

\section{CONCLUSIONS}

The analytical method used for organic $\mathrm{Hg}$ determination proved to be efficient and was validated by the results of the reference material analyzed. The methodology showed no analite in the blanks and resulted in good standard deviation values $(<20 \%)$.

The method adapted for Organic Hg quantification in sediment samples presented efficiency with recovery levels ranging from 84 to $112 \%$. No interference problems of $\mathrm{Hg}^{+2}$ presence in the range of 1 to $5 \mathrm{mg} \mathrm{L}^{-1}$ were detected. No inorganic $\mathrm{Hg}$ transfer was observed during the organic $\mathrm{Hg}$ extraction.

The procedure for the uncertainty measurement showed to organic $\mathrm{Hg}$ can also be applied to any other organic or methylmercury extraction similar to that which was presented in this study and include all the main variables that make up the total uncertainty. The organic extraction step is the step that most contributes for the uncertainty calculations, depending only on each researcher using the obtained uncertainty by standard deviation of the reference materials analyses or using the entire calculation for organic $\mathrm{Hg}$ uncertainty carried out in the present study.

This analytical method for $\mathrm{Hg}$ speciation in environmental samples can be applied in laboratories without any sophisticated equipment for $\mathrm{Hg}$ determination. Only a CVAAS is needed. The LQ obtained ( $3.3 \mu \mathrm{g} \mathrm{kg}^{-1}$, wet basis) by using this analytical methodology 
is not too low when compared to literature values but it can be easily employed in sediment samples which are contaminated with $\mathrm{Hg}$.

\section{ACKNOWLEDGMENTS}

The authors wish to thank Dr. E. G. Moreira from IPEN and Dr. J. R. Costa from CETESB for their valuable comments and suggestions regarding the technical aspects of this study.

\section{REFERENCES}

1. Nevado, J. J. B.; Martin-Doimeadios, R. C. R.; Bernardo, F. J. G.; Moreno, M. J.; Anal. Chim. Acta 2008, 608, 30.

2. Porcella, D. B. In Mercury Pollution: Integration and Synthesis; Watras, C. J.; Huckabee, J. W., eds.; Lewis Publishers: Boca Raton, 1994, cap. 1.

3. Rudd, J. W. M.; Water, Air, Soil Pollut. 1995, 80, 697.

4. Bisinoti, M. C.; Jardim, W. F.; Quim. Nova 2004, 27, 593.

5. Baird, C.; Química ambiental, Bookman: Porto Alegre, 2002.

6. Azevedo, F. A.; Toxicologia do mercúrio, Rima: São Carlos, 2003.

7. http://www.ambicare.com/downloads/minamata_case_study.pdf, acessada em Julho 2011.

8 Hintelmann, H.; Wilken, R. D.; Sci. Total Environ. 1995, 166, 1.

9. WHO (World Health Organization); Methylmercury (Environmental Health Criteria: 101), WHO: Geneva, 1990.

10. Canario, J.; Antunes, P.; Lavrado, J.; Trends Anal. Chem. 2004, 23, 799.
11. Leemarkers, M.; Bayeyens, W.; Quevauviller, P.; Horvat, M.; Trends Anal. Chem. 2005, 24, 383.

12. Martin-Doimeadios, R. C. R.; Monperrus, M.; Krupp, E.; Amouroux, D.; Donard, O. F. X.; Anal. Chem. 2003, 75, 3202.

13. Bisinoti, M. C.; Jardim, W. F.; Brito Júnior, J. L.; Guimarães, J. R.; Quim. Nova 2006, 29, 1169.

14. Hammerschimidt, C. R.; Fitzgerald, W. F.; Anal. Chem. 2001, 73, 5930.

15. Delgado, A.; Prieto, A.; Zuloaga, O.; Diego, A.; Madariaga, J. M.; Anal. Chim. Acta 2007, 582, 109.

16. http://www.epa.gov/waterscience/methods/method/mercury/1630.pdf, acessada em Julho 2011.

17. http://www.epa.gov/epawaste/hazard/testmethods/sw846/pdfs/3051a. pdf, acessada em Julho 2011.

18. http://www.epa.gov/epawaste/hazard/testmethods/sw846/pdfs/3015a. pdf, acessada em Julho 2011

19. INMETRO; Vocabulário Internacional de Termos Fundamentais e Gerais de Metrologia, INMETRO: Duque de Caxias, 1995.

20. INMETRO; Guia para a expressão da incerteza de medição, $3^{a}$ ed. brasileira em língua portuguesa, INMETRO, ABNT: Rio de Janeiro, 2003.

21. Bloom, N. S.; Colman, J. A.; Barber, L.; Fresenius J. Anal. Chem. 1997, 358,371 .

22. Hintelmann, H.; Chemosphere 1999, 39, 1093.

23. Falter, R.; Hintelmann, H.; Quevauviller, P.; Chemosphere 1999, 39, 1039.

24. Horvat, M.; Bloom, N. S.; Liang, L.; Anal. Chim. Acta 1993, 281, 135. 